\title{
Designed to Welcome Death Rather Than Life
}

\author{
Ahotovi Ahoto Thomas* \\ West Africa Healthcare Services Improvement Centre, Ghana \\ *Corresponding author: Ahotovi Ahoto Thomas, The Greens Foundation, West Africa Healthcare Services Improvement Centre, The Greens Foundation \\ Tema, Greater Accra Region, Ghana
}

Submission: 眥April 18, 2018; Published: 眥 April 25, 2018

\section{Opinion}

I have being observing how hospital environment look like for some time now, one unique feature of hospital is how equable the whole environment is design. Health profession from old till date has remain a profession that only handful have knowledge about. Health professionals are well respected because of the knowledge they which is limited to other professionals. As the professional knowledge of health is limited so is the knowledge about the hospital and equipment also limited to none health professionals.

Moving to the hospital to seek treatment can sometime be confusing, especially if there are no clear directions showing where patients to report to or when there is language barrier. Unlike going to other places like hotels where there are people ready to help us to get what we want, in terms of hospital the visitor have to approach the health workers themselves and act so sober if he or she is to get the needed attention. Hospital are mostly sellers' market where the seller is powerful than the buyers (hospital workers are powerful than patients).

Hospital environment are design in complex nature making it difficult to understand, though one can move from shop to shop to do window shopping by so doing gaining more knowledge are become familiar with the shop and its product, we only have access to the hospital when we are sick or escorting relative for treatment. Going to the hospital has never been a pleasant journey for anyone apart for the hospital workers, because going to the hospital is like going to environment where return alive is not always assured.
Since onedo not go to the hospital dead, hospitals must be design to give hope to life than giving hope to death. Hospital environment should be an open place for the public to visit even if they are not sick, though there can be limit to where public can get access to in the hospital, combining hospital and other businesses such as shops, restaurant, game centre can bring down the tension that exist in the entire hospital environment.

Hospital machine and equipment can be scaring when look at for the first time, the names and terminologies use around these machines also sound scaring and imply fear to none hospital workers. Educating patients about the name of these machines and their uses can help reduce the fear they have seeing these machines. Not everybody who attend the hospital as sick person will come back alive, but it is better for the hospital to show hope of the sick getting better even if in reality there is no such hope.

Hospital design must be relook at, the entire environment of hospitals can be redesign to bring some hope of life to patients, colours used to paint the hospital must depict hope, there can wall hanging that also portray positive things, nice music in the hospital environment with humanize hospital workers can speed up healing. Focusing on professionalism, equipment and medical efficacy have been the dominant factor in hospitals with less attention being pay to other social conditions that can boost healing.

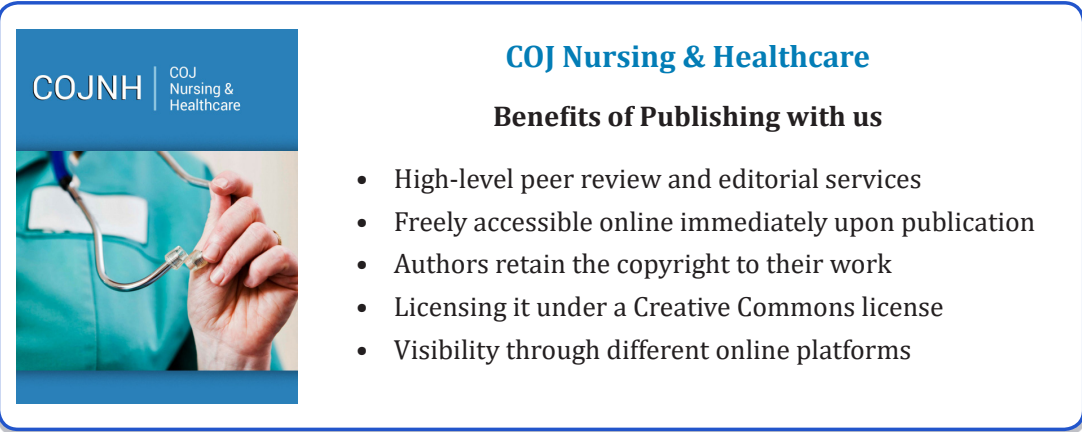

